\author{
Süreyya Bulut \\ Aydın Adnan Menderes University, bsureyya@gmail.com, Aydın-Turkey \\ Leyla Khorshid \\ Ege University, khorshidleyla@gmail.com, Izmir-Turkey \\ Mehmet Polatlı \\ Aydın Adnan Menderes University, mpolatliog@gmail.com, Aydın-Turkey
}

\begin{tabular}{l|l|l|l|l}
\hline \hline DOI & http://dx.doi.org/10.12739/NWSA.2021.16.2.1B0114 & \\
\hline ORCID ID & $0000-0002-3813-8203$ & $0000-0001-7101-9014$ & $0000-0001-7917-4297$ \\
\hline Corresponding Author & Süreyya Bulut & \\
\hline
\end{tabular}

\title{
THE EFFECT OF UPPER EXTREMITY EXERCISES ON DYSPNEA AND LIFE QUALITY IN PATIENTS WITH CHRONIC OBSTRUCTIVE PULMONARY DISEASE
}

\section{ABSTRACT}

Dyspnea is the most important symptom of chronic obstructive pulmonary disease (COPD). Training and exercise in symptom management improve the physical and psychological condition of patients, increase their compliance with treatment and quality of life. In this study, it was aimed to determine the effect of upper extremity exercises performed by a specialist nurse without using extra tools on dyspnea. The study was conducted with 78 patients with COPD, including 39 exercise and 39 control group. The patients in exercise group carried out upper extremity exercise for 30 minutes, 3 times a week throughout 8 weeks and the clinical course of the control group was not interfered. At the end of 8 weeks, patients were compared in terms of their symptom scores and scale point averages. Patient Identification Form, Saint George Respiratory Questionnaire, Medical Research Council, Modified Borg Scale, COPD Evaluation Test, 6- minute walk test distance criteria and oxygen saturation measurements were used in the collection of data. It was discovered that of the participants involved in the study, 92.3\% of cases were males, the average age in

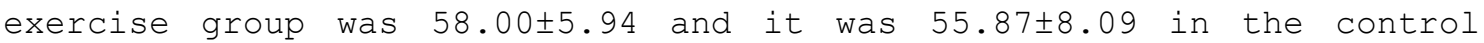
group. In the 8 th week, it was observed that the distance increased for the majority of patients in exercise group in 6-minute walk and with regard to COPD evaluation test, Medical Research Council, Modified Borg Scale dyspnea score average reduced. Upper extremity exercises that had been regularly applied to patients with COPD for 8 weeks under the supervision of attending nurse were observed to be effective in elevating patients' life quality.

Keywords: COPD, Dyspnea, Nursing, Upper Extremity Exercise, Pulmonary Dísease

\section{INTRODUCTION}

Chronic obstructive pulmonary disease (COPD) is a preventable and treatable disease characterized by permanent respiratory symptoms and airflow limitation based on airway and/or alveolar abnormalities developed as a result of significant exposure to mostly harmful gases and particles [1]. Dyspnea in advanced cases is the leading cause of anxiety and labour loss related to COPD. Even though its effect is different in every patient, the quality of life is impaired depending on the severity of shortness of breath. The restrictions of dyspnea and the course of disease on daily life activities; change in emotional, cognitive and physical activities; economical and social constraints leave patients face to face with difficult and complex

How to Cite:

Bulut, S., Khorshid, L., and Polatlı, M., (2021). The Effect of Upper Extremity Exercises on Dyspnea and Life Quality in Patients with Chronic Obstructive Pulmonary Disease. Medical Sciences, 16(2):122-131, DOI: 10.12739/NWSA.2021.16.2.1B0114. 
problems [2]. Particularly shortness of breath, exacerbations and deterioration of accompanying diseases cause patients to reduce their daily activities and in advancing periods they lead to social isolation, anxiety, depression and deconditioning; as a result, patient's life quality and length of life are negatively affected [3, 4, 5, 6, 7 and 8]. Programmes to eliminate psychological and behavioral problems as well as pharmacological treatments in reducing symptoms and exacerbations of patients with COPD play a substantial role in nonpharmacological approach $[4,9,10,11,12$ and 13]. Patients experiencing frequent exacerbations are recommended to participate in a complete Pulmonary Rehabilitation (PR) programme considering their individual and comorbid diseases [14 and 15].

Given pulmonary rehabilitation nonpharmacological interventions, it has been observed that its application remains inadequate worldwide despite its favourable and cost-effective feature [16 and 17]. According to a study carried out by Turkish Thorax Association (TTA) Pulmonary Rehabilitation and Chronic Care Study Group, a total of 35 hospitals and centers are existing for PR application in our country. Primary patient-related restrictions such as limited number of application centers, transportation difficulty, ventilator dependence or being bedbound confine the implementation of controlled PR programmes in the hospital [14].

The individuals with COPD typically breath through upper airway and they use accessory respiratory muscles rather than diaphragm. Therefore, they usually have a difficulty in upper extremity activities [4 and 7]. Although upper extremity activities seem to be unrelated to dyspnea and respiration, upper extremity exercises are able to reduce dyspnea by decreasing lung function capacity along with a change in respiratory functions and chest wall mechanic [4, 7, 16 and 17]. While the ideal exercise programme duration is not accurately known in persons with COPD, exercise capacity and dyspnea are dependent on application frequency and time. In literature, pulmonary rehabilitation programme period must be 8 weeks and every session must be at least 30 minutes long and 3-5 times a week. Recoveries and effects in long term programmes are sustained [9, 12, 18, 19 and 20]. The ergometers used in exercise programmes are costly and unavailable and it forms a disadvantage in every place. Therefore, unsupportive upper extremity exercises which are more similar to daily life activities are mentioned in literature [20 and 21].

Exercise training, an important part of rehabilitation, comprises respiratory muscle training, lower extremity and upper extremity trainings. Upper extremity exercises have been dealt with in a limited number of studies to date and it is stated in the guideline prepared by American Cardiovascular and Pulmonary Rehabilitation Association that controlled studies are required in evaluating their effectiveness [17 and 20]. Nurse plays a significant role in sustaining and improving health with his/her "trainer role" among other contemporary roles and rehabilitation of chronic diseases. Under the conditions that every patient is not able to reach pulmonary training programmes in our country, practicing training on the person with COPD is of great importance for nurse to enhance the functional condition of the patient [2, 4, 7 and 20]. Reduction of dyspnea and depending on this, development of life quality must take part in nursing care. Thus, it was aimed to determine the effect of upper extremity exercises that had been regularly practiced by a specialist nurse on dyspnea and life quality and discuss the significance of specialized COPD care nursing in nonpharmacological approach of COPD management. 


\section{RESEARCH SIGNIFICANCE}

The study results in question are of importance in that raising awareness as an uncostly method (upper extremity exercises) which can be easily applied to patients with COPD in reducing dyspnea, increasing the use of it and forming a proof regarding its benefits to be obtained from patient applications are greatly likely to contribute to the symptoms and life quality of patients as well as health expenditures in the national economy positively.

\section{THE QUESTIONS OF THE RESEARCH}

- Is there an impact of upper extremity exercises carried out for 8 weeks on dyspnea in patients with COPD?

- Is there an effect of upper extremity exercises performed for 8 weeks on life quality of patients with COPD?

- Is there an effect of upper extremity exercise on some physiological parameters applied for 8 weeks in patients with COPD?

\section{MATERIAL AND METHODS}

\subsection{The Purpose of Research And Its Type}

This study was carried out to study the effect of toolles upper extremity exercise performed for 8 weeks in patients with COPD on life quality and some physiological parameters and is a prospective, randomized controlled, experimental type research with pretestposttest measurements. Power analysis was performed to establish the sample size of the research and the minimum number of samples was 32 including 16 implementation and 16 control group [16]. Nonetheless, the research was carried out with 78 patients (39 experiment, 39 control patients) compatible with the inclusion criteria to ensure the generalizability of sample size research outcomes. The power of study was identified as 97\% compared to current data in terms of dyspnea prevalence with 5\% margin of error.

\subsection{Outcome Measurements}

In the collection of research data; questionnaire developed by researchers, Saint George's Respiratory Questionnaire (SGRQ), Medical Research Council (MRC) and Modified BORG Dyspnea scale to evaluate dyspnea severity, COPD Evaluation Test (COPD Assessment Test - CAT) were used and Pulmonary Function Test, 6-Minute Walking test (6MWT) were applied.

- Question Form: The form in which indicative features of patients such as their age, sex, residency place, education, income level, employment status, marital status, the people with whom they live, the existence of chronic diseases were questioned and it contained questions (19 questions) $[4,9,16,21,22,23,24$, 25, 26 and 27].

- St. George Respiratory Questionnaire (SGRQ) : It was developed by P.W. Jones in 1992 to assess the life quality in lung diseases. SGRQ questions containing 50 articles are divided into 2 parts: symptoms ( 8 articles), activities (16 articles) and effects of the disease (26 articles). 3 parts of the test are scored separately and total scores are calculated. Total score varies from 0 (perfect health) to 100 (the most severe disease), scorechange ranging 4 and over based on treatment is clinically regarded as significant [7, 28 and 29].

- Medical Research Council Dyspnea Scale (MRC): Fletcher (1959) is a scale with 5 articles formed to group patients according to their dyspnea severity and based on various physical activities 
that are similar to dyspnea. The articles in the scale range as following: 1 (no dyspnea except for strenuous exercise) - 5 (there is dyspnea even in daily activities) [26 and 30].

- Modified Borg Scale (MBS): It was developed by Borg in 1970 to measure the effort during exercise. It is composed of 10 articles in accordance with the severity of dyspnea including 0 (no dyspnea) - 10 (the most severe dyspnea) [26 and 30].

- COPD Assessment Test (СAT): It is a test consisting of 8 questions measuring the impairment in health condition of COPD assessment. Its aim is to reveal the severity of disease by showing the impact of COPD with sum of scores obtained from a patient. If the test score is within 0-10 range, it is considered as low; if it is within 21-30, it is high; if it is very high, it is evaluated as effective [28 and 31].

- Six-Minute Walk Test (6MWT): It is an easily achievable test showing exercise capacity objectively. How far (meter) patient is able to walk in six minutes is measured. The patient is rested 10 minutes before the test. In the determination of treatment efficiency of COPD patients, minimum clinical alteration value is accepted as 32-71 meters in 95\% confidence interval $[21,22,23,24,25$ and 27].

\section{INTERFERENCE}

Patients who had referred to Chest Polyclinic for routine control and been diagnosed with COPD were determined to be classified as exercise/control group in a randomized way, COPD assessment scale test (CAT) was applied by obtaining informed consent with introductory information and St. George respiratory questionnaire by interviewing face to face and dyspnea severity of the patient was evalauted with MRC at that moment. Patients were rested in sitting position for 15 minutes and after their vital signs (blood pressure, pulse, respiratory rate) and oxygen saturation had been measured, respiratory function test was carried out; 6-min walk test was performed in the aftermath of $30-\mathrm{min}$ rest and all results were written in patient follow-up form.

Toolles upper extremity exercise was performed to application group by the researcher for 8 weeks lasting 3 times a week and 20 minutes; on the other hand, no exercise programme was applied to control group; only measurements were carried out and normal clinical protocol was not intervened. Exercise and control group patients were asked to visit polyclinic on determined dates after 8th week of application ended; St. George's respiratory questionnaire and COPD assessment scale test (CAT) were performed in control group and dyspnea severity of the patient was evaluated with MRC. Patients were rested in sitting position for 15 minutes and after their vital signs (blood pressure, pulse, respiratory rate) and oxygen saturations had been measured, respiratory function test was carried out; 6-min walk test was applied following 30 -min rest and all results were noted in patient's follow-up form.

\section{STATISTICAL ANALYSIS}

In the evaluation of research data; Statistical Package for the Social Sciences (SPSS) for Windows 16.0 package programme was utilized. Introductory information associated with patients was presented as number, percentage and average. The homogeneity of experiment and control groups was analysed with chi square test and it was determined that groups were homogenous. Kruskall-Wallis test, Wilcoxon Sign test and Pearson's Correlation test were used in the 
Bulut, S., Khorshid, L., and Polatlı, M. Medical Sciences, 2021, 16(2):132-131

analysis of data. Statistical significancy level was accepted as $\mathrm{p}<0.05$.

\section{RESULTS}

When distribution of patients included in the study was examined according to their personal and disease characteristics; it was discovered that in exercise group average age was 58.00土5.94 (age

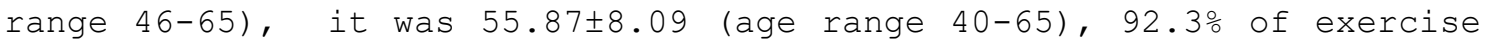
and control group were male, 53.8\% of exercise group and 61.5\% of control group patients were primary school graduates, no difference was identified in terms of variables between chi-square test performed, exercise and control groups, 59.0\% of exercise group and 38.5\% of control group were employed, 94.9\% of exercise group and 89.7\% of control group were married. It was identified that patients had been diagnosed with COPD in exercise group for $1.82 \pm 1.50$ years and $1.84 \pm 1.06$ years in control group, they had no additional disease except for COPD with 71.8\% in exercise group and 51.3\% in control group. It was found out that $76.9 \%$ of exercise group patients smoked in any period of their lifetime and the average age in terms of smoking initiation was $18.96 \pm 1.99$ and it was $18.70 \pm 1.80$ in control group patients. It was determined that average smoking cessation age was $51.73 \pm 7.20$ years in exercise group and it was $50.76 \pm 6.97$ years in control group. It was identified that the number of average daily cigarette use for smokers was $13.00 \pm 4.27$ in exercise group and it was $13.50 \pm 4.18$ in control (Table 1 ).

Table 1. Distribution of patients according to their smoking behaviors

\begin{tabular}{|l|c|c|}
\hline Smoking History & $\begin{array}{c}\text { Exercise Group ( } \mathrm{n}=39) \\
\text { Mean } \pm \text { SD (min-max) }\end{array}$ & $\begin{array}{c}\text { Control Group (n=39) } \\
\text { Mean } \pm \text { SD (min-max) }\end{array}$ \\
\hline Smoking Initiation Age & $18.96 \pm 1.99(13-22)$ & $18.70 \pm 1.80(15-22)$ \\
\hline Smoking Cessation Age & $51.73 \pm 7.20(33-62)$ & $50.76 \pm 6.97(39-60)$ \\
\hline Daily Cigarette Use & $13.00 \pm 4.27(10-20)$ & $13.50 \pm 4.18(10-20)$ \\
\hline
\end{tabular}

It was discovered that score average of patients on the 8 th week of SGRQ evaluating life quality of patients in lung diseases was $36.57 \pm 14.10$ in exercise group, $43.65 \pm 15.58$ in control group and the difference was determined to be statistically significant in MannWhitney $U$ test (MWU=563.0, $\mathrm{p}=0.048, \mathrm{p}<0.05)$ (Table 2).

Table 2. Distribution of patients according to the difference between sgrq and subscale mean scores after 8 week

\begin{tabular}{|c|c|c|c|c|}
\hline \multirow[b]{2}{*}{ Patient Group } & SGRQ Subsc & e Score Average & $(\mathrm{X}+\mathrm{SD})$ & \multirow{2}{*}{$\begin{array}{c}\text { Scale Total } \\
\text { Score Average } \\
\text { (min-max) }\end{array}$} \\
\hline & $\begin{array}{c}\text { Symptom Score } \\
\text { Average }\end{array}$ & $\begin{array}{c}\text { Activity Score } \\
\text { Average }\end{array}$ & $\begin{array}{c}\text { Effect } \\
\text { Score Average }\end{array}$ & \\
\hline $\begin{array}{l}\text { Exercise Group } \\
(\mathrm{n}=39)\end{array}$ & $47.24 \pm 3.12$ & $43.31 \pm 2.36$ & $29.38 \pm 2.56$ & $\begin{array}{l}X=36.57 \pm 14.10 \\
(10.94-73.79)\end{array}$ \\
\hline \multirow{2}{*}{$\begin{array}{l}\text { Control Group } \\
(n=39)\end{array}$} & $58.33 \pm 2.96$ & $49.53 \pm 2.87$ & $35.70 \pm 2.68$ & $\begin{array}{c}X=43.65 \pm 15.58 \\
(23.03-64.71)\end{array}$ \\
\hline & \multicolumn{4}{|l|}{$\mathrm{MWU}=563.0$} \\
\hline
\end{tabular}

The differences on 0 th and 8th week; SGRQ, CAT, MRC, BORG score averages of exercise and control group patients and 6 MWT distances were found statistically significant with Mann Whitney Test $(p<0.05)$ (Table 3). In addition, the distance measurements of 6 MWT on 0 th and 8 th week of exercise group were of clinically importance. While a reduction was observed in CAT score averages on 8 th week compared to 0th week in $43.6 \%$ of control group patients, a decrease was seen in CAT score averages on 8 th week of $84.6 \%$ of exercise group patients and the difference between alterations in Wilcoxon signed Rank test was not statistically significant ( $Z=-1.241 \quad \mathrm{P}=0.215 \mathrm{P}>0.05)$. It was found 
out that partial oxygen saturation of patients in exercise group was

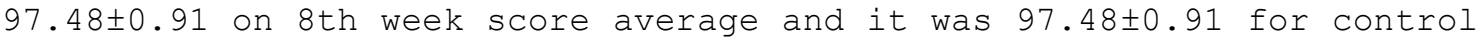
group patients. This difference was not statistically significant in Mann-Whitney $U$ test (MWU=760.5, $\mathrm{P}=1.00, \mathrm{P}>0.05)$.

Table 3. Distribution of the patients according to their mean SGRQ, CAT, MRC, BORG, PFT, 6MWT score difference between 0 and 8 weeks

\begin{tabular}{|l|c|c|c|}
\hline & $\begin{array}{c}\text { Exercise Group (n=39) } \\
\text { X+SD (min.-max) }\end{array}$ & $\begin{array}{c}\text { Control Group (n=39) } \\
\text { X+SD (min.-max) }\end{array}$ & $\begin{array}{c}\text { MWU } \\
\text { P }\end{array}$ \\
\hline SGRQ Difference & $-7.46 \pm 8.55$ & $-2.28 \pm 8.78$ & 220.0 \\
Score Average & $(-36.52-10.43)$ & $(-38.73-0.00)$ & 0.000 \\
\hline CAT Difference & $-3.00 \pm 2.94$ & $-0.64 \pm 2.41$ & 381.5 \\
Score Average & $(-11.00-1.00)$ & $(-8.00-3.00)$ & 0.000 \\
\hline MRC Difference & $-1.82 \pm 0.75$ & $-0.05 \pm 0.60$ & 51.5 \\
Score Average & $(-4.00-0.00)$ & $(-1.00-1.00)$ & 0.000 \\
\hline BORG Difference & $-2.41 \pm 1.09$ & $-0.05 \pm 1.14$ & 107.0 \\
Score Average & $(-5.00-0.00)$ & $(-2.00-3.00)$ & 0.000 \\
\hline 6MWT Average & $34.56 \pm 42.96$ & $0.76 \pm 9.63$ & 182.0 \\
Distance Difference & $(-70.00-160.00)$ & $(-20.00-20.00)$ & 0.000 \\
\hline
\end{tabular}

\section{DISCUSSION}

This research was of experimental type and carried out to study the effect of toolles upper extremity exercise on dyspnea, life quality and some physiological parameters performed for 8 weeks ( 3 days a week and 30 minutes each time) in COPD patients. It was found out that upper extremity exercises performed for 8 weeks ( 3 days a week regularly) were influential in decreasing dyspnea that patients had been experiencing. The difference between SGRQ, CAT, MRC, BORG score averages of 0 th and 8 th week of COPD patients in upper extremity exercise group and 6 MWT distances was found significant and these results were determined to be of clinically value.

While there was no statistically and clinically significant alteration in SGRQ score averages at the end of 8 th week of control group patients, there was a statistically and clinically significant decrease in SGRQ score averages of exercise group patients and an increase was observed in the life quality of COPD patients along with exercise programme. The difference between 8 th week SGRQ score averages of exercise and control groups was found statistically and clinically significant and life quality of patients on whom exercise had been applied increased more compared to that of control group. The findings obtained from the study show parallelism with other study findings $[10,25,32,33$ and 34]. Our study and other study results emphasize that supportive applications in addition to medical treatment have a favourable effect in increasing life quality of patients.

While CAT score average reduced in the majority of exercise group after 8 weeks in the research, it was vice versa in the control group. However, the difference of 8 th week CAT score averages between groups was statistically identified as insignificant. Our study findings show similarity with the study of Tülüce, et al., (2016) in which they analyzed the effect of patient coaching on some symptoms of COPD patients [31]. Although the positive alteration in CAT score averages of exercise group patients in our research was not statistically significant, the decrease in disease severity experienced individually is thought to be caused by regularly performed exercise programme. CAT aimig to evaluate the disease individually cannot be compared with different studies since it cannot be used with other scales. It was found out that the difference between MRC and BORG Dyspnea Scale score averages after 8 th week related to exercise and control group patients was statistically 
significant and there was a reduction in experienced dyspnea. The findings obtained from the study display parallelism with study results performed [23 and 25].

In a study that Gökoğlu et al (2006) evaluated the effectiveness of pulmonary rehabilitation programme in COPD patients; it was found that the difference between 0 th and 8 th week measurement results of BORG dyspnea scale was statistically significant in pulmonary rehabilitation patient group, however, insignificant in control group patients [16]. In a study that Alkan et al (2006) conducted with 25 COPD patients to examine the efficiency of home rahabilitation programme in COPD; it was determined that there was a decrease in the first and last measurement value of BORG dyspnea scale and this reduction was significant [22]. In a study carried out by Gigliotti et al (2005), it was established that BORG dyspnea score was statistically significant in terms of the difference regarding averages that was before and after exercise programme [19]. This study's results displaying similar findings with our study show that different exercise and home-assisted programmes in addition to medical treatment were effective for patients in reducing dyspnea which is the most important symptom of disease.

The difference of 6 MWT averages on the 8 th week in terms of exercise and control groups is found as significant both statistically and clinically. It is noticed that upper extremity exercise programme carried out regularly was beneficial in decreasing the effect of disease by increasing the walking distance together with medical treatment. The results of other studies in literature also support our study findings [21, 22, 23, 24, 25 and 27].

No statistically significant relation was found between partial oxygen saturation and BORG dyspnea scale in our study. In a study conducted by Güneş et all. (2012), no significant correlation was determined between partial oxygen saturation value and BORG dyspnea scale value [26]. While these findings show similarity with each other, it demonstrates that there is no immediate response in the saturation value despite reduction in respiratory distress. The alterations in these results are thought to be followed with long term studies in this patient group.

In conclusion, our study results suggest that upper extremity exercises applied for 8 weeks ( 3 days a week regularly) in COPD patients were discovered to be efficient in reducing dyspnea that patients had gone through. Disease management is substantial in chronic diseases leading to disability like COPD commonly observed all over the world. In the management of this, specialized health personnel including not only doctor, but also nurse and physiotherapist is required in this field. However, we observe that nursing service is mostly ensured as general health care. Actualization of post graduate programmes in certain areas following undergraduate education will directly and indirectly contribute to reduction of costs owing to improvement in the disease and their life quality.

By educating specialist nurses in the area of pulmonary medicine by planning certification programs and facilitating their active participation in nonpharmacological treatment, it is thought that it will be possible to manage the COPD symptoms effectively and complications, and yield a reduction in the burden of this disease in health economics. In addition to these results, the effect of application of upper extremity exercises to COPD patients in proper setting of clinic is recommended to be analyzed for different diseases depending on dyspnea. This research was supported by University Scientific Research Projects as ASYO-12001 numbered project. This 
research was presented as oral bulletin in 15th National Nursing Congress organized by Atatürk University in Erzurum on september 2015 and it was deemed worthy of "Oral Bulletin Winner". There is no conflict of interest.

\section{MAIN POINT}

- Dyspnea is an important symptom in the life quality of a patient in COPD, and $P R$ is useful in reducing dyspnea.

- Pulmonary Rehabilitation reported to be effective in the administration of symptoms appearing along with COPD is a comprehensive programme and it increases their compliance with medication, life quality by improving patients' physical and psychological conditions. However, it has been observed that these units are absent or inadequate in many health institutions.

- Under the conditions that every patient is not able to reach pulmonary training programmes in our country, practicing training on the person with COPD is of great importance for nurse to enhance the functional condition of the patient.

- In conclusion, our study results suggest that upper extremity exercises applied by a specialist nurse for 8 weeks ( 3 days a week regularly) in COPD patients were discovered to be efficient in reducing dyspnea that patients had gone through and in increasing their life quality.

\section{INFORMED CONSENT}

A written informed consent was obtained from all patients who participated in this study.

\section{AUTHOR CONTRIBUTIONS}

1.Conception - S.B.; 2.Design - S.B.-L.K., M.P.; 3.Supervision S.B.,L.K.,M.P.; 4.Fundings: S.B., L.K.; 5.Materials - S.B.; 6.Data Collection and/or Processing - S.B.; 7.Analysis and/or Interpretation - S.B.-L.K.,M.P.; 8.Literature Search - S.B.-L.K.; 9.Writing - S.B.; 10. Critical Reviews - S.B.-L.K.,M.P..

\section{CONFLICT OF INTEREST}

The authors declared no conflict of interest.

\section{FINANCIAL DISCLOSURE}

The authors declare that this study has received no financial support.

\section{ETHICAL COMMITTEE APPROVAL}

Written consent (18th October 2011-2615 numbered script) was obtained from Research and Training Hospital and Aydın Adnan Menderes University Medicine Faculty Clinical Research Ethics Committee (Protocol Number:2011/038) and it was supported as ASYO-12001 numbered project by University Scientific Research Projects. For "Saint George's Respiratory system Questionnaire" used as a data collection tool in the research, written consent was acquired from Prof Dr. Türkan Tatlıcıoğlu, lecturer of Gazi University Chest Diseases Department and for COPD Assessment Test, Glaxo Smith Kleine that has the right of use regarding the scale was contacted by e-mail and their permission was attained. Written consent was obtained from the patients making up the sampling group of research with volunteering principle. Patients' problem concerning transportation to hospital was 
solved via a regular transportation vehicle with financial support of the project.

\section{REFERENCES}

[1] Global Initiative for Chronic Obstructive Lung Disease (GOLD) . Global strategy for the diagnosis, management and prevention of COPD. 2017. Available from: URL: http://goldcopd.org.

[2] Taylor, C., Lillis, C., Le Mone, P., et al., (2008). Fundamentals of nursing-the art and science of nursing care. Philadelphia: Lippincott Williams, pp:235-68.

[3] Janaudis-Ferreira, T., Hill, K., Goldstein, R., et al., (2009). Arm exercises training in patients with chronic obstructive pulmonary disease. J Cardiopulm Rehabil Prev, 29:277-83.

[4] Çil, A. and Olgun, N., (2005). COPD management with pulmonary rehabilitation. J Ege University Nursing Faculty, 21(1):103-11.

[5] Paulin, Ei, Yamaguti, W.P.S., Chammas, M.C., et al., (2007). Influence of diaphragmatic mobility on exercise tolerance and dyspnea in patientswith COPD. Respir Med, 101:2113-18.

[6] Sin, D.D., Anthonisen, N.R., Soriano, J.B., et al., (2006). KOAH' mortalite: komorbiditelerin rolü. Eur Respir J, 28:12451257.

[7] Gökçek, Ö., Hüzmeli, D.E., and Katayıfçı, N., (2019). The effect of dyspnea on quality of life and depression in patients with chronic obstructive pulmonary disease. Acibadem University Health Sciences Journal, $10(1): 84-8$.

[8] Ekenler, S. and Arslan, S., (2019). Illness perception and related factors in patients with chronic obstructive pulmonary disease. Journal of Anatolia Nur. and Heal. Sci., 22 (3) : 151-60.

[9] Akıncı Çil, A. and Pınar, R., (2012). Dyspnea rehabilitation in patients with chronic obstructive pulmonary disease. Cumhuriyet Nursing Journal, 1:24-9.

[10] Jardim, R.J., (2007). Nascimento AO. pulmonary rehabilitation. Respir Med. 5:21-7.

[11] Yenilmez, Ö., Gürsoy, S., Evyapan, F., et al., (2018). Analysing activity participation and quality of life in subjects with chronic obstructive pulmonary disease. Elderly Issues Research Journal, $11(2): 30-6$.

[12] Nguyen, Q.H., Carrier-Kohlman, V., Rankin, H.S., et al., (2005). Is internet-based support for dyspnea self-management in patients with chronic obstructive pulmonary disease possible? results of a pilot study. Heart Lung, 34(1):51-62.

[13] Skumlien, S., Hagelund, T., Bjortuft, O., et al., (2006). A Field Test of Functional Status as Performance of Activities of Daily Living in COPD Patients. Respir Med, 100:316-23.

[14] Köktürk, N., Gürgün, A., Şen, E., et al., (2017). Türk Toraks Derneği'nin GOLD Kronik Obstrüktif Akciğer Hastalığı (KOAH) Raporuna bakışı. https://www.toraks.org.tr/uploadFiles/book/file /1042017161917-tumu.pdf.

[15] Şen, E. ve Bartu, S.S., (2005). KOAH epidemiyolojisi doğal gelişim risk faktörleri. Bartu SS, Acıcan T, editors. KOAH Tanı ve Tedavi, Güncel Akciğer hastalıkları Serisi-12. Ankara: Bilimsel Tıp Yayınevi, pp:9-23.

[16] Gökoğlu, F., Bilgin, G., Okumuş, M., et al., (2006). The outcomes of short term outpatient pulmonary rehabilitation in chronic obstructive Pulmonary Disease. Turk Thorac, 7 (3):173-7.

[17] Thomas, A.L., (2009). Effective dyspnea management strategies identified by elders with end-stage chronic obstructive pulmonary disease. Appl Nurs Res, 22:79-85. 
[18] Erk, M., (2009). KOAH ve pulmoner rehabilitasyon. Toraks Kitapları:7. Ístanbul: Aves Yayıncılık; p:117-28.

[19] Gigliotti, F., Coli, C., Bianchi, R., et al., (2005). Arm exercise and hyperinflation in patientswith COPD: Effect of Arm Training. Chest, $128(3): 1225-32$.

[20] Atasever, A., (2011). Pulmoner rehabilitasyonda egzersiz. http: / / 168.144.121.167/TORAKSED23NJKL4NJ4H3BG3JH/mse2-ppt-pdf / 5 alev-atasever-word.pdf.

[21] Akıncı Çil, A., (2008). KOAH'lı bireylere uygulanan pulmoner rehabilitasyonun fiziksel ve psikolojik parametrelere etkisi. Marmara University Institute of Health Sciences, Department of Internal Medicine Nursing PhD thesis.

[22] Alkan, H., Sarsan, A., Topuz, O., et al., (2006). Effectiveness of home rehabilitation programme in chronic obstructive pulmonary disease. Turk J Phys Med Rehab, 52 (2):51-4.

[23] Bianchi, R., Gigliotti, F., Romagnoli, I., et al., (2011). Impact of a rehabilitation program on dyspnealntensityand quality in patients with chronic obstructive pulmonary disease. J Clin Invest, 81:186-95.

[24] Elçi, A., (2006). Kronik obstrüktif akciğer hastalıklarında verilen sağlık eğitimi ve pulmoner rehabilitasyonun yaşam kalitesi ve solunum fonksiyonlarına etkisi, Gaziantep University Institute of Health Sciences Master thesis.

[25] Levent, Ö. ve Gürsel, K.Y., (2003). Kronik obstrüktif akciğer hastalığında pulmoner rehabilitasyonun etkinliğinin değerlendirilmesi. Romatizma. 18:1-7.

[26] Güneş, Y.ü., Kara, D., and Erbağcı, A., (2012). Comparison of the dyspnea scales in patients with complaints of dyspnea. EJournal of Dokuz Eylul University Nursing Faculty, 5 (2):65-71.

[27] Sarpkaya, Ü., Tuna, H., Altıay, G., et al., (2004). Effect of ventilatory muscle training and aerobic exercise program in chronic obstructive pulmonary disease on respiratory functional test and arterial blood gases. Rheumatology. 19(3):165-71.

[28] Jones, P., Lareau, S., and Mahler, D.A., (2005). Measuring the effects of COPD on the patient. Respir Med, 99(2):11-8.

[29] Polatlı, M., Yorgancıoğlu, A., Aydemir, Ö., et al., (2013). Validity and Reliability of Turkish Version of St. George's Respiratory questionnaire. Tuberk Toraks. 61(2):81-7.

[30] Kara, D. and Yıldız, H., (2013). Effectiveness and frequencies of dyspnea scales in evaluating symptom of dyspnea. Gumushane University Journal of Health Science, $2(1)$ :137-49.

[31] Tülüce, D., KutluTürkan, S., Çetin, N., et al., (2016). The effect of the patient coaching on the dyspnea, cough and sputum symptoms of the monitored patients with Chronic obstructive Pulmonary Disease (COPD): A pilot study. Gumushane University Journal of Health Science, 5(2):32-41.

[32] Hospes, G., Bossenbroek, L., Hacken, H.T.N., et al., (2009). Enhancement of daily physical activity increases physica fitness of outclinic COPD Patients: Results of an Exercise Counseling Program. Patient Educ Couns, 75:274-8.

[33] Wadell, K., Sundelin, G., Henriksson-Larsen, K., et al., (2004). High Intensity physical group training in water-an effective training modality for patients with COPD. Respir Med, 98:428-38.

[34] Taşdemir, Z.A., Börekçi, Ş., Demir, T., et al., (2009). The effect of physiotherapy and nutrition on pulmonary function tests, exercise capacity and quality of life inpatients with chronic obstructive lung disease. Cerrahpaşa Medical Journal, 40 ( 4 ) : $129-35$. 